\title{
IMPACT OF PETROLEUM ON SMES GROWTH IN NIGERIA
}

\author{
Sam, B.A. TENDE, Ph.D \\ Department of Business Administration \\ Faculty of Administration \\ Nasarawa State University, Keffi \\ tende_sam@yahoo.com \\ Ezie OBUMNEKE \\ Department of Economics \\ Faculty of Humanities, Social and Management Sciences \\ Bingham University, Karu, Nasarawa State \\ eobumneke@yahoo.com
}

\begin{abstract}
The study undertakes an empirical research on the impact of petroleum on small and medium scale enterprises (SMEs) development in Nigeria. The log linear error correction model was adopted to examine how petroleum price (PP), Imported petroleum (IMP) and domestically produced petroleum (DPP) had impacted on Nigeria's SMEs. Unit root test was carried out on each of the variables to determine their level of stationarity. They were however found stationary after first difference (that is, they are all integrated of order one (I(1)), then it was safe to proceed with Johansen Cointegration Test. The integrated variables were then used for the regression analysis. The cointegration result showed that the variables used in the model have a long term, or equilibrium relationship between them. It was observed that from the analysis that PP and IMP were found to be statistically insignificant and both had negative relationships with SMEs development Nigeria, while DPP had a positive impact and is statistically significant. Due to the underproduction of the Nigerian petroleum refineries, the government had to resort to importation of the shortfall which also has its cost implications on its sales and distribution. Local manufacturers and farmers had to pay more for transporting their goods and services to the markets. Incessant price hikes of petroleum products have led to crisis and industrial actions led by some pressure groups in Nigeria which has caused distortion in the SMEs activities of Nigeria overtime The study thus recommends that the down-stream oil need to be deregulated to allow private investors come in to build in more refineries so as to produce the petroleum at a relatively lower cost to propel the growth of SMEs in the country.
\end{abstract}

\section{INTRODUCTION}

Oil is a major source of energy in Nigeria and the world in general. Oil being the mainstay of the Nigerian economy plays a vital role in shaping the economic and political destiny of the country. Although Nigeria's oil industry was founded at the beginning of the century, it was not until the end of the Nigeria civil war (1967 - 1970) that the oil industry began to play a prominent role in the economic life of the country.

The Nigerian petroleum industry has been described as the largest among all industries in the country. This is probably due to the belief that petroleum is one of the major sources of energy 
worldwide. The size, international characteristic, and role assumed by the petroleum industry were noted to have originated from the notion that petroleum is versatile as it currently satisfies a wide variety of energy and related needs. Petroleum is the most vital source of energy, providing over 50 percent of all commercial energy consumption in the world. The revenues obtained from crude oil in Nigeria are of absolute advantage to expenditure commitments on various projects at the local, state, and federal levels. (Onaolapo, Taiwo \& Adegbite, 2013)

Crude oil discovery has had certain impacts on the Nigeria Small and medium scale enterprises (SMEs) both positively and adversely. On the negative side, this can be considered with respect to the surrounding communities and businesses within which the oil wells are exploited. Some of these communities and small businesses still suffer environmental degradation, which leads to deprivation of means of livelihood and other economic and social factors. Although large proceeds are obtained from the domestic sales and export of petroleum products, its effect on the growth of the SMEs as regards returns and productivity is still questionable, hence, the need to evaluate the relative impacts of petroleum on SMEs growth in Nigeria.

The problems with Nigerian economy have been traced to failure of successive governments to use oil revenue and excess crude oil income effectively in the development of other sectors of the economy especially the small scale businesses (Yakub, 2008). Over all, there has been poor performance of national institutions such as power, energy, road, transportation, politics, financial systems, and investment environment have been deteriorating and inefficient (Nafziger, 2008).

This paper therefore seeks to examine the impact of petroleum on SMEs growth in Nigeria

\section{LITERATURE REVIEW}

\subsection{The Concept of Oil Sector Development}

Various literatures have identified economic development as efforts that seek to improve the economic well-being and quality of life for a community by creating jobs and supporting or growing incomes and the tax base. Dominant theories of economic growth have suggested that significant relationship exist between national income and economic growth. That is, when income is invested in an economy, it results in the growth of that economy. For example, Harrod (1939) and Domar (1946) models state that growth is directly related to savings (unspent income). Similarly, Ogbonna \& Appa (2012) observed that income from a nation's natural resources (e.g. petroleum) has a positive influence on economic growth and development. Contrary to this opinion expressed above, other studies on this subject matter, found that natural resources income influences growth negatively. That is, an increase in Income from natural resources does not necessarily result in an increase in economic growth. For example, Sachs and Warner (1997) using a sample of 95 developing countries that included Indonesia, Venezuela, Malaysia, Ivory Coast and Nigeria, found that countries that have a high ratio of natural resource exports to GDP which appears to have shown slower economic growth than countries with low ratio of natural resource export to GDP.

In theory, proponent of oil-led development (as an example Eromosele, 2004) observed that countries lucky enough to have petroleum, can base their development on this resource. They point to the potential benefits of enhanced economic growth and the creation of jobs, increased government revenues to finance poverty alleviation, the transfer of technology, the improvement of infrastructure and the encouragement of related industries. But the experience of almost all oilexporting countries to date, especially Nigeria illustrates few of these benefits (Omeje, 2006). To say the least, Nafziger (1984) says that Nigeria's case is increasingly degenerating to a state of chaos as petroleum income is brazenly mismanaged while the basic national institutions such as 
electricity, energy, road, transportation, political, financial systems, and investment environment have been decreasing and inefficient in Nigeria, the infrastructure is still poor; talent is scarce. Poverty, famine, and disease afflict many nations, including Nigeria (Chironga, et al, 2011)

\subsection{The Concept of SME}

Various literature exists on Small and Medium Enterprises (SMEs) written by various authors and in different languages and for various purposes. This fact underscores the essence, importance and relevance of this sub-sector in the development of any given economy. The experiences of developed economies in relation to the roles played by SMEs cannot be overemphasized especially among the Less Developed Countries (LDCs) or rather developing country like Nigeria. SMEs have been variously referred to as the "engine of growth", this stems from the fact that almost all countries that have focused on the SMEs sector and ensures its vibrancy have ended up succeeding in the significant reduction and its attendant enhancement in the quality and standard of living, reduction in crime rate, increase in per capita income as well as rapid growth in GDP among other salutary effects (Mordi, 2005).

According to allbusiness.com (2010), the abbreviations SME's occurs commonly in the European Union and in international organizations such as World Bank, the United Nations and the World Trade Organizations. Also the term Small and Medium Scale Businesses (SMEs) is predominantly used in the United States of America. The European United States traditionally has their own definition of what constitutes SMEs. For instance, the traditional definition in Germany limit Small and Medium Scale Enterprises to two hundred and fifty (250) employees while in Belgium, it is limited to one hundred (100) employees. Recently, the European union has standardize the concept by categorizing enterprises with less than ten (10) employees as "Micro" those with fewer than fifty (5) employees as "Small" and those with fewer than two hundred and fifty (250) employees as medium". In the United States of America, any business with fewer than one hundred (100) employees is classified as "small" while medium scale business refers to a business with fewer than five hundred (500) employees.

In Nigeria, micro and small enterprise play a pivotal role in the overall industrial economy of the country. It is estimated that in terms of values, the sector account for about $39 \%$ of the manufacturing output and about $33 \%$ of the total export of the country. Also in South Africa, the term small, medium and micro enterprises (SMMEs) are usually used. While in Nigeria, the term small and medium scale enterprise (SMEs) is generally used. From the foregoing, it can be deduced that small and medium scale enterprises are enterprises that have the capacity to employ at most five hundred (500) employees at a time and it has been proved to be the backbone of every economy. The brain behind every successful small and medium scale enterprises is entrepreneurship is an undertaking in which one is involved in the task of creating and managing an enterprise for a purpose. The purpose of further stated may be personal, social or developmental. One who is involved in this task is called an entrepreneur. Also a line between an entrepreneur and business owners must be drawn while business owners establish and manage their own enterprise for personal gains, entrepreneurs exploit ideas that create a business that benefit them, the society and act as development weapon (Olagunju, 2004).

Histrich and Peters (1998) explained that the study of entrepreneurship has relevance today, not only because it helps small business or entrepreneur, better fulfil their personal needs, but also because their economic contribution of the new ventures, their study therefore sees SMEs as a positive force. In economic growth and development, Ekanem (2006) summarizes the importance of SMEs to include ensuring rapid development, increased utilization of local resources and provision of a training ground for indigenous managers and semi-skilled workers reduction of the rural-urban drift, development of indigenous technology and raising the living standard of rural 
dwellers and so on. In fact, SMEs accounts for the economic development in most developed economics of the world today. It has helped in the balance of payment position of countries; it reduces over dependences on inputs relative to their Capital Investment. A study by Ekpenyong (1997) showed that very little financial supports have been provided by the traditional Financial Institutions (the Commercial Banks) to the SMEs. The reasons are that small businesses have serious inherent structural defects that make them high risks borrowers and the traditional banks are not structured to cater for the type of credit demanded by the small businesses owing to the nature of their credit assessment procedures (Hammend, 1995).

There is a consensus that if all stakeholders are to show serious commitment to the development of the SMEs Sub-Sector, it follows that the economy must necessarily witness meaningful transformation and prosperity. A dynamic SME sub-sector is vital and imperative for the overall economic development of the country. Aside from providing opportunities for employment generations, SMEs help to provide effective means of curtailing rural-urban migration and resource utilization.

\subsection{The Performance of the Oil Sector in Nigeria}

The Nigerian oil sector can be categorized into three main sub-sectors, namely, upstream, downstream and gas. The most problematic over the years has been the downstream sector, which is the distribution arm and connection with final consumers of refined petroleum products in the domestic economy. The incessant crisis in supply of products culminated in the decision by Government in 2003 to deregulate the downstream sub-sector. However, the manner of its implementation has been controversial because it ignores the economic realities in Nigeria. Oil production by the joint venture (JV) companies accounts for about $95 \%$ of Nigeria's crude oil production. Shell, which operates the largest joint venture in Nigeria, with $55 \%$ Government interest (through the Nigerian National Petroleum Corporation, NNPC), produces about $50 \%$ of Nigeria's crude oil. Exxon Mobil, Chevron Texaco, ENI/Agip and Total, Elf operate the other JV's, in which the NNPC has $60 \%$ stake (Idowu, 2005)

The over-dependence on oil has created vulnerability to the vagaries of the international market, as observed in the preceding section that show the contribution of oil to some macro-economic variables.

In particular, the place of oil in the mind of the average Nigerian has become more profound since the deregulation of the downstream segment of the Nigerian oil industry in 2003. The contradiction is more glaring now with the recent rise in crude oil prices at the global markets, which meant more external earnings for Nigeria, but also increased the expense burden on imported refined petroleum products! It is such contradictions that make the Nigerian economy appear strange at times, as policies seem to ignore what appears obvious to do. As such, policies designed to address the deficiencies and defects in the structure end up being poorly articulated and/or implemented because of regional, political or rent-seeking selfish interests.

Obviously, it is the same rent-seekers that continually sabotage the reinvigoration of the domestic refineries, making Nigeria to depend on importation of refined products to meet the domestic need. At present, Nigeria has four refineries, with a combined installed refining capacity of 445,000 barrels per day (bpd).

The combined capacities of these refineries exceed the domestic consumption of refined products, chief of which is premium motor spirit (gasoline), whose demand is estimated at 33 million litres daily. The refineries are however, operating far below their installed capacities, as they were more or less abandoned during the military era, skipping the routine and mandatory turnaround 
maintenance that made products importation inevitable. Importation notwithstanding, there have been persistent product shortages that gave strength to the argument for deregulation of the downstream oil subsector in Nigeria.

The monetization of oil revenue has been a major factor in liquidity management in Nigeria. Measuring liquidity as the narrow and broad money definitions by the CBN, the early 1990s saw increases that were dampened by 1995 up until the civilian administration came on board in 1999 . The new Government maintained disciplined fiscal operations for about one year and thereafter, the floodgates were opened. Since then, the CBN has been battling to keep liquidity in check, in order to ensure that it does not create adverse effects on the three key macroeconomic prices (i.e., interest rate, exchange rate and inflation rate). The greatest challenge is when Nigeria generates more revenue from crude oil sales than it budgeted, like now. Such excesses have always been monetized, creating market distortions and inflationary pressure [Iyoha, 2007].

The same argument goes for deficit fiscal operations in comparison to the GDP. The pattern of this ratio indicates the optimism that accompanies increase in oil revenue and makes Government to engage in frivolous spending or unnecessary projects. Deficit spending invariably makes Government resort to borrowing from the Central Bank through the instrument of Ways and Means Advances, which later convert into short term debt instruments that are quite expensive to service at market rates.

At this point, there is sufficient ground to examine how economic policy formulation has been impacted or induced by petroleum oil in Nigeria. As much as possible, major economic policies since Nigeria gained political independence would be examined vis-a-vis the state of the oil sector. This should provide adequate basis for making a few specific recommendations on how to reduce the dependency.

\subsection{Empirical Literature}

Empirically studies have been have provided results showing the impact of natural resources on small business growth. Some of these studies not only reported that resource abundance had positive impact on growth and development but also found that resource dependence had no adverse impact on growth.

Several empirical studies have confirmed the natural resource curse hypothesis. Some other reasons why resource-rich countries might suffer resource curse are reduced returns to human investments, precipitated by natural resource exploitation (Gylfason, 2001) and poor economic management that leads to inefficient resource allocation among business e (Rosser, 2006). All in all, while there are strong theoretical grounds to suspect a broad correspondence between natural resource abundance especially oil and low growth, the nature of the linkage is neither direct nor simple. Empirical literature has not provided conclusive answer to whether abundant natural resource is a curse or blessing. Even among studies that claimed the curse of natural resources actually exist, there is no agreement on what exactly drives the curse of the natural resources and on how it exactly plays out. This explains why further research should be focused on the causal link between natural resource abundance and SMEs growth in the resource rich economies.

Petroleum is no doubt a predominant source of Nigeria's revenue and foreign exchange. Previous studies on the Nigeria economy in the last decade show that the petroleum industry has been playing a dominant role and occupies a strategic position in the SMEs development of Nigeria (Azaiki and Shagary, 2007). This is evidenced by the total oil revenue generated into the Federation Account from 2000 to 2009 which amounted to N34.2 trillion while non-oil was N7.3 trillion, representing $82.36 \%$ and $17.64 \%$ respectively. The mean value of oil revenue for the 10 year period is N3.42 trillion compared to non-oil revenue at N732.2 billion (Central Bank of Nigeria, 2011). 
Further evidence was ten year's average crude oil and condensates production of 832,866,752.1 barrels from 2000 to 2009. The importance of crude oil to the SMEs development of Nigeria cannot be over emphasized, Nigeria gained an extra \$390 billion in oil-related fiscal revenue between 1971 and 2005 (Central Bank of Nigeria, 2011).

Unfortunately, the SMEs has been bedeviled by sustained underdevelopment evidenced by poor human developmental and economic indices including poor income distribution, militancy and oil violence in the Niger Delta, endemic corruption, unemployment, relative poverty (Baghebo, 2012). Irrespective of Nigeria's huge oil wealth, the SMEs has remained highly underdeveloped. Despite the fact that crude oil has been the source of Nigerian economy, the economy is faced with high rate of unemployment, wide spread oil spillage, increasing poor standard of living, low per capita income and high rate of inflation which (Baghebo, 2012).

\section{RESEARCH METHODOLOGY}

\subsection{Estimation Procedure/Method of Data Analysis}

The research work made use of the econometric approach in estimating the relationship between Petroleum and the Nigerian SMEs growth. The dependent variable is SMEs contribution to real Gross Domestic Product while the independent variables are petroleum price (PP), imported petroleum (IMP) and domestically produced petroleum (DPP). The Ordinary Least Square (OLS) technique was used in obtaining the numerical estimates of the coefficients in different equations using e-views. The OLS method is chosen because it is the best linear unbiased estimator. The estimation period cover 1993 to 2013.

The data for this study was obtained mainly from secondary sources, particularly from Central Bank of Nigeria (CBN) Statistical Bulletin, CIA fact fish and NNPC statistical bulletin. We adopt two stage methodologies in this study. First the stationary status of the data series was examined using Augmented Dickey Fuller unit root test. This is followed by Johansen cointegration test.

Research design is the structure and strategy for investigating the relationship between the variables of the study. The research design adopted for this work is the experimental research design. The reason is that experimental research design combines the theoretical consideration with empirical observation. It enables a researcher therefore to observe the effects of explanatory variables on the dependent variables

\subsection{The Structural Regression Model}

This section is preoccupied with the formulation of an appropriate model, which theoretically establishes the relationships between our petroleum variables and SMEs development variable. For this purpose, the equation below have been formulated and simultaneously analyzed:

$$
S M E G=f(P P, I M P, D P P)--------1
$$

Specifying equation (1) in an exponential regression model, we have;

$$
S M E G=\phi P P^{\beta_{1}} I M P^{\beta_{2}} D P P^{\beta_{3}} e^{\mu_{t}}-------2
$$


In this form, the coefficients $\beta_{1}, \beta_{2}, \beta_{3}$ can be directly estimated by applying log-linear regression techniques via logarithmic transformation; and those coefficients will be the elasticities. Taking natural logs of both sides of the equation, we have:

$\ln S M E G=\ln \phi+\beta_{1} \ln P P+\beta_{2} \ln I M P+\beta_{3} \ln D P P+\mu_{t}-------3$

Where;

$\mathbf{l n}=$ Natural logarithm

$\phi=$ is the autonomous parameter (or the intercept)

SMEG = SMEs contribution to GDP

$\boldsymbol{P P}=$ Petroleum price

$\boldsymbol{I M P}=$ Imported petroleum

$\boldsymbol{D P P}=$ Domestically produced petroleum

$\mu_{t}=$ represents the stochastic error term.

\section{RESULTS AND DISCUSSION OF EMPIRICAL FINDING}

\subsection{Unit Root/Stationarity Test Results}

Macroeconomic time series data are generally characterized by stochastic trend which can be removed by differencing. Unit root test therefore is a test of stationarity or non-stationarity of series data used in the model. This is to find out if the relationship between economic variables is spurious or nonsensical. This test is conducted by adding the lagged values of the dependent variable so that the error term is serially uncorrelated. Thus, this paper used or adopted Augmented Dickey-Fuller (ADF) Techniques to test and verify the unit root property of the series and stationarity of the model.

The result is presented in Table 4.1 below.

\section{Table 1 Summary of Unit Root Test Results}

\begin{tabular}{|l|l|l|}
\hline Variables & ADF Test Statistic(at first difference) & Order of Integration \\
\hline$S M E G$ & $-6.075895(-4.284580)^{*}$ & $I(1)$ \\
\hline$P P$ & $-12.01805(-4.374307)^{* *}$ & $I(1)$ \\
\hline$I M P$ & $-3.693498(-3.622033)^{* *}$ & $I(1)$ \\
\hline$D P P$ & $-5.929077(-4.296729)^{*}$ & $I(1)$ \\
\hline
\end{tabular}

Source: Authors Computation, 2014 (Eview-7): Note: (a) MacKinnon critical values for the rejection of hypothesis of unit root are in parenthesis in Columns 2 and the tests include intercept and trend; the star imply $1 \%$, and $5 \%$ level of significance.

As shown in Table 4.1, the ADF unit root tests indicate that the null hypothesis of unit root is rejected at first difference for two of the variables at $1 \%$ level of significance, with the exception of PP and IMP which were found stationary at 5\%(ADF). Thus all the variables are stationary at first difference as the case may be. The stationary values shall be used for the analysis. 


\subsection{Co-integration Test}

If two or more time series are not stationary, it is important to test whether there is a linear combination of them that is stationary. Economically, variables are cointegrated if they have a long term, or equilibrium relationship between them. It is a pretest to avoid spurious regression situations. It is possible for a combination of some series to achieve long run equilibrium; although they may be individually non-stationary. This phenomenon is referred to as the test for cointegration(Gujarati and Porter, 2009). The evidence of cointegration implies that there is a long run relationship among the variables

\section{Table 2 Results of Johansen Multivariate Cointegration Test}

Date: $10 / 18 / 14$ Time: $14: 20$

Sample (adjusted): 19932013

Included observations: 33 after adjustments

Trend assumption: Linear deterministic trend

Series: SMEG, PP, IMP, and DPP

Lags interval (in first differences): 1 to 1

Unrestricted Cointegration Rank Test (Trace)

\begin{tabular}{ccccc}
\hline \hline $\begin{array}{c}\text { Hypothesized } \\
\text { No. of CE(s) }\end{array}$ & Eigenvalue & $\begin{array}{c}\text { Trace } \\
\text { Statistic }\end{array}$ & $\begin{array}{c}0.05 \\
\text { Critical Value }\end{array}$ & Prob.** \\
\hline \hline None * & 0.683043 & 58.58979 & 47.85613 & 0.0036 \\
At most 1 & 0.321893 & 22.97109 & 29.79707 & 0.2475 \\
At most 2 & 0.293778 & 18.92916 & 15.49471 & 0.0159 \\
At most 3 & 0.004717 & 0.146576 & 3.841466 & 0.7018 \\
\hline \hline
\end{tabular}

Trace test indicates 2 cointegrating eqn(s) at the 0.05 level

$*$ denotes rejection of the hypothesis at the 0.05 level

***MacKinnon-Haug-Michelis (1999) p-values

Unrestricted Cointegration Rank Test (Maximum Eigenvalue)

\begin{tabular}{ccccc}
\hline \hline $\begin{array}{c}\text { Hypothesized } \\
\text { No. of CE(s) }\end{array}$ & Eigenvalue & $\begin{array}{c}\text { Max-Eigen } \\
\text { Statistic }\end{array}$ & $\begin{array}{c}0.05 \\
\text { Critical Value }\end{array}$ & Prob.** \\
\hline \hline None * & 0.683043 & 35.61870 & 27.58434 & 0.0038 \\
At most 1 & 0.321893 & 12.04194 & 21.13162 & 0.5435 \\
At most 2 & 0.293778 & 17.78258 & 14.26460 & 0.0654 \\
At most 3 & 0.004717 & 0.146576 & 3.841466 & 0.7018 \\
\hline \hline
\end{tabular}

Max-eigenvalue test indicates 2 cointegrating eqn(s) at the 0.05 level

* denotes rejection of the hypothesis at the 0.05 level

**MacKinnon-Haug-Michelis (1999) p-values

\section{Source: Authors Computation, 2014 (Eview-7)}

The Johansen cointegration test results (both the trace test and the maximum eigenvalue test) show that the variables are cointegrated. Therefore we will conclude that there is a long-run or equilibrium relationship among PP, IMP, and DPP 


\subsection{Analysis of Findings and Policy Implications}

This section is pre-occupied with the presentation of result and interpretation of the empirical results. From our earlier stated regression model, we have:

$$
\ln S M E G=\ln \beta_{0}+\beta_{1} \ln P P+\beta_{2} \ln I M P+\beta_{3} \ln D P P+\mu---------------3
$$

The regression result is presented in table 4.3 below:

$$
\begin{aligned}
& S M E G=-0.82-2.46 P P-0.19 I M P+0.44 D P P---------------4 \\
& S E E=\quad \begin{array}{llll}
0.06 & 1.26 & 0.11 & 0.12
\end{array} \\
& t^{*}=\quad-0.12-1.95 \quad-1.67 \quad 3.40 \\
& F^{*}=6.92 ; \operatorname{Prob}(\mathrm{F} \text {-statistic })=0.28 \\
& R^{2}=0.97 ; \text { Adj. } R^{2}=0.83 \\
& D W=2.01
\end{aligned}
$$

The F-statistics examines the overall significance of a regression model. Therefore, by examining the overall fit and significance of the model, it can be observed that the model does not have better fit, as indicated by a lower value of the $F$-statistic, 6.92 and it is insignificant at the 5.0 per cent level. That is, the F-statistic value of 0.28 is greater than 0.05 .

The $R^{2}$ (R-square) value of 0.97 shows that the model has a very good fit. It shows that proper variables capturing the activities of the petroleum and SMEs sector was utilized. It indicates that about 97 per cent of the variation in SMEs growth is explained by petroleum price, imported petroleum and domestic petrol production, while the remaining unaccounted variations of 3 percent are captured by the error term.

Durbin Watson statistics is used to test for the presence of autocorrelation. The model also indicates that there is no autocorrelation among the variables as indicated by Durbin Watson (DW) statistic of 2.01. This shows that the estimates are unbiased and can be relied upon for policy decisions.

Studying the regression model, it could be observed that PP is statistically insignificant and more so contributes negatively to the growth of SMEs in Nigeria. It shows an increase in petroleum price dwindle the performance of SMEs in the country. Most time when government increases the price of premium motor spirit (PMS), it normally altered or causes fluctuation to supply and distribution of the product. The marketers tended to gain more during this period thereby causing artificial scarcity of the product throughout the country. This is in-line with the findings of Adeleke(2012) who stated that price increase of PMS leads to increase in cost of production and distribution of other commodities including agricultural products. The findings revealed that most prices of other commodities skyrocketed as transportation fare rose during price increase of PMS. Local manufacturers and farmers had to pay more for transporting their goods and services to the markets; this resulted in increase in price of PMS which caused increase in transportation fare thereby leading to increase in the cost of commodities. The function thus shows that a 1percent increase in petroleum price (PP) decreases the growth of SMEs by 2.46percent. This is consistent with findings in previous studies such as Arenze (2011), Ougunbodede, Ilesanmi and Olurankinsa (2010) who have also posited that incessant price hikes of petroleum products have led to crisis and industrial actions led by some pressure groups in Nigeria which has caused distortion in the SMEs activities of Nigeria overtime. 
The imported petroleum (IMP) was also found to be statistically insignificant and contributed negatively to the growth and performance of SMEs in Nigeria. Due to the underproduction of the Nigerian refineries, the government had to resort to importation of the shortfall which also has its cost implications on its sales and distribution. The independent marketers cause an artificial scarcity after buying these imported shortfalls to make more gain. This explains why the IMP has had insignificant influence on the growth of SMEs in Nigeria. This collaborates with the findings of Arenze(2011) who noted that this slow movement of imported petroleum, coupled with the limited quantity transportable through tankers, created shortages, which caused long queues in filling stations across the country and bred black marketing, therefore made small scale businesses to pay exorbitant prices. The model thus showed that a 1percent change in imported petroleum dampens the growth of SMEs by 0.19 percent.

Finally, only domestically produced petroleum (DPP) was found to be statistically significant and had contributed positively to the growth of SMEs in Nigeria. The function shows that a 1percent increase in domestic petroleum production increases the performance of SMEs in Nigeria by 0.44 percent.

\section{CONCLUSION AND RECOMMENDATION}

The petroleum industry has grown steadily over the years to become the cornerstone of the nation's economy in recent times. Since the 1970s, the nation's crude oil Industry has contributed immensely to the government's revenue profile. In addition to dominating other sectors, the oil industry has accounted for the bulk of the nation's revenue and foreign exchange reserves. However, its displacement of SMEs as a major contributor to the growth of the economy has created structural imbalances for the economy, undermining economic performance and national development.

In Nigeria, the focus of the reform should be for the oil and gas institutional structures and regulatory framework to maximize the economic benefits of petroleum resources, which could enhance reduced cost of production and operations of SMEs. The policy should facilitate economic prosperity for small business growth in Nigeria through petroleum price reduction. The caveat issue to keep in mind is that the petroleum downstream sector deregulation ought to be deregulated in other to ensure production efficiency, effective and equitable, which could result in durable infrastructures and optimal petroleum pricing for sustainable SMEs development.

\section{REFERENCES}

Adeleke, D.O (2012) Global Crisis Facing Petroleum Products Distribution. Intel Publications Ltd.

Arenze, P.E. (2011). Energy consumption and Economic Growth in Nigeria. Trancampus Journalof Jorind ISSN 1596-8308.

Azaiki \& Shagary (2007). Oil, Gas and Life in Nigeria. Ibadan: Y - Books

Baghebo, M (2012). Natural Resource Economics. Bayelsa: Kadmon Printing Press and Publishing House.

Central Bank of Nigeria. (2011). Central Bank of Nigeria Statistical Bulletin. Abuja: Central Bank of Nigeria.

Chironga, M. Leke, A. Lund, S. and Wamelen, A. V. (2011) "Cracking the Next Growth Market: Africa”, Collection,Northern Kentucky University Congerssional Research Service.

Ekanem, N. F. (2006) "A Case for Integrating Technology into Small 
Enterprises Development in Nigeria". Review of Business Information Systems, 10, (4), pp. 51-54.

Ekpenyong D. B. (1997) "Problems of Small Business and Why they Fail".

Journal of General Studies, Bayero University, 3(1)

Eromosele, V. E. (2004) "Nigeria and the Challenge of Oil Wealth" Port Harcourt, The Institute of Chartered Accountants of Nigeria (ICAN) 2004 Mandatory Continuing Professional Education

(MCPE) Programm.

Gujarati, D. \& Porter, D. (2009). Basic Econometrics, $5^{\text {th }}$ Edition. New York: McGraw-Hill. Harvard Business Review, May 2011. pp. 117.

Gylfason, T. (2001). Natural resources, education and economic development. European Economic Review, 45: 847-859.

Hammend, P. (1995), "Magnitude and Demand for Credit by SMEs". A paper presented at the West African Sub-regional Seminar on Enterprises Credit, Accra Ghana, March, $15-17$.

Histrich, S. and Peters, A. L. (1998) "Obstacles to Development Indigenous Small and Medium Enterprises", an empirical assessment.

Idowu, K.O. (2005). A Preliminary Investigation into the Causal Relationship between Exports and Economic Growth in Nigeria. CBN Economic and Financial Review, 43(3): 29-50

Iyoha, M.(2007). "Oil price fluctuations and the Nigerian economy", Texas, United States,the Jesse H. Jones School of Business, Texas Southern University, Houston.

Mordi, F. (2005), Manufacturers, CBN Disagree on causes of SME's stunted growth, Financial Standard, Millennium Harvest Ltd, Lagos. Allbusiness.com (2010).

Nafziger, E. W. (1984). "'The Economics of Political Instability: The Nigerian- Biafran War. Boulder, Colo":: Westview Press.

Ogbonna,G.N \& Appa,E (2012). Petroleum Income And Nigerian Economy: Empirical Evidence.

Arabian Journal of Business and Management Review (OMAN Chapter) Vol. 1(9)

Olagunju, Y. A. (2004), Entrepreneurship and Small Scale Business Enterprises Development in Nigeria, Ibadan University Press Plc.

Omeje, K.( 2006) "High Stakes and Stakeholders: Oil Conflict and Security in Nigeria". Aldershot: Ashgate Publishing.

Onaolapo A. Abdul-Rahamoh1, Fasina H. Taiwo2, Adegbite T. Adejare(2013). The Analysis of the Effect of Petroleum Profit Tax on Nigerian Economy. Asian Journal of Humanities and Social Sciences (AJHSS) Volume 1 - Issue 1,

Orgunbodede, E.F, Ilesanmi, A.O. and Olurankinsa, F. (2010). Petroleum Price Crisis and the

Nigerian Public Transportation System. Medwell journals of social sciences. Scientific Research

Publishing Company.

Sachs ,M., \& Warner, O. (1997). Natural Resource Export and Economic Growth of Selected countries, Journal of Economic Review.2(4)

Rosser, A. (2006). The political economy of the resource curse: A literature survey. IDS Working Paper 268.

Yakubu, M. (2008) “The Impact of Public Sector Financial Management on the Economies of Sub-Saharan-Africa",40(2010)@Euro-Journals.Publishing,Inc.2010,http//www,euro journals, com/finance.htm. 